\title{
Correction to: Using Causal Inference in Field Development Optimization: Application to Unconventional Plays
}

\author{
Antoine Bertoncello ${ }^{1}$ • Georges Oppenheim ${ }^{2}$. Philippe Cordier ${ }^{3}$. \\ Sébastien Gourvénec $^{3}$ - Jean-Philippe Mathieu ${ }^{1}$ - Eric Chaput ${ }^{1}$. \\ Tobias Kurth ${ }^{4}$
}

\section{Correction to: Math Geosci https://doi.org/10.1007/s11004-019-09847-z}

Unfortunately, in the original version of the article the first and second name of the fourth author were wrong. Furthermore the sequence of first and second names of authors was not in accordance with the journal style: first name, second name.

The original article has been corrected.

The original article can be found online at https://doi.org/10.1007/s11004-019-09847-z.

$凶$ Antoine Bertoncello

antoine.bertoncello@total.com

1 Total S.A., Avenue Larribau, 64000 Pau, France

2 Laboratoire de Mathématiques d'Orsay, Université Paris-Sud, 5 Rue Georges Clemenceau, 91400 Orsay, France

3 Total S.A., 8 Avenue de la Vauve, 91120 Palaiseau, France

4 Institute of Public Health, Charité - Universitätsmedizin Berlin Charitéplatz 1, 10117 Berlin, Germany 